\title{
Matrix Converter for Induction Motor Drive
}

\author{
Pravin G. Dhawale, Sushil D. Gaurkhede
}

\begin{abstract}
This paper presents the comparison of performance between matrix converter and conventional DC-link converter fed induction motor drive system. It is noted that conventional converter required two stages for power conversion whereas matrix converter required single stage. The output current from conventional converter contains odd harmonic component which produces additional losses in drive causes de-rating and torque pulsation of motor. This unhealthy operation of drive is reduced by matrix converter which has the unique feature of producing pure sinusoidal output current waveform with minimum harmonic distortion. The main objective of this paper is to reduce total harmonic distortion by employing proper switching of matrix converter. The simulated result is compared with conventional converter to show that proposed system is better than conventional system. This paper also presents modeling and simulation of matrix and conventional converter fed induction motor drive system using MATLAB/SIMULINK software.
\end{abstract}

Keywords : Conventional DC-link converter, Matrix converter, Switching strategy, Modelling, Total Harmonic Distortion Analysis, Torque Pulsation.

\section{INTRODUCTION}

Induction motor (IM) play a vital role in the industrial sector especially in the field of electrical drives and control. Such popularity takes place due to its simple construction and robustness. Since speed-torque characteristic of IM depends on supply frequency and applied voltage.

Converter usually has functions of voltage regulation, protection and drive control. Main function of converter is to generate controllable sinusoidal AC outputs in terms of variable magnitude and frequency from fixed AC supply. The main efforts which elaborates converter are usually directed to the increasing of converter efficiency and improving the quality of the output voltage by reducing the higher harmonics. AC - AC converters should be divided into two types: indirect AC - AC converters and direct AC - AC converter [3]-[4].

Conventional DC-link converter belongs to indirect AC-AC converter whereas matrix converter (MC) is a family member of direct converter. DC-link converter required two stages for power conversion with massive bulky energy storage capacitor whereas MC required single stage. MC required bi-directional switches (BDS) but there is no need for conventional converter.

Revised Manuscript Received on February 05, 2020.

* Correspondence Author

Mr. Pravin G. Dhawale, Assistant Professor, Sanjay Ghodawat University, Kolhapur, INDIA

Mr.Sushil D. Gaurkhede, Assistant Professor, ITM-College of Engineering,Nagpur smoussa@cud.ac.ae

(C) The Authors. Published by Blue Eyes Intelligence Engineering and Sciences Publication (BEIESP). This is an open access article under the CC BY-NC-ND license (http://creativecommons.org/licenses/by-nc-nd/4.0/)
The serious drawback of DC-link converter is output current contained higher order harmonic. Harmonic losses not only reduces efficiency but also increase motor derating, which produces thermal over loading of IM even at light load condition [5]-[6]. Another major drawback of odd harmonic contained in supply current produces torque pulsation of IM [7]. All above disadvantages of DC-link converter causes due to harmonic distortion which are reduced by MC fed IM drive system. The unique feature of MC is to produce pure sinusoidal output current waveform with minimum harmonic distortion by employing proper switching strategy [9].

The main objective of this paper is to analysis THD of both the converter and its effect on IM drive. The performance has been analyzed on the basis of torque pulsation and motor derating.

\section{CONVENTIONAL DC-LINK CONVERTER FED INDUCTION MOTOR DRIVE}

Three phase conventional DC-link converter consist of rectifier and inverting circuit which is coupled by energy storage capacitor as shown in Fig.1. Rectifier circuit consists of three legs six switches uncontrolled diode bridge. Inverter circuit consists of three legs fully controlled (IGBT/MOSFET) switches.

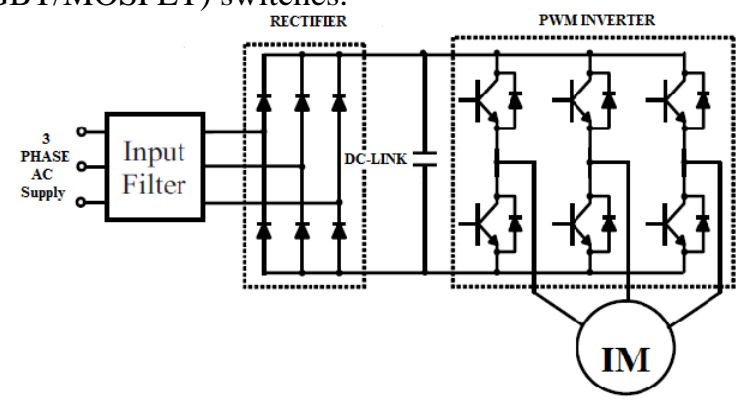

Fig. 1 Conventional DC-link converter fed induction motor

Conventional converter has some constructional draw back are follows:

1) size/volume ratio high due to presence capacitor

2) restricted to be used in high temperature application

3) no regeneration capability due unidirectional operation of diode bridge

4) output supply contained dc harmonic component

Among all these disadvantages conventional DC-link converter has some practical advantages such as

1) simple in construction

2) no need of BDS

3) simple modulation strategy which makes it to be used in industrial application 


\section{A. WORKING OPERATION OF DC-LINK CONVERTER}

In first stage, input AC supply is converted into constant DC voltage which is store in capacitor. The magnitude of DC voltage is depending upon peak value of input voltage (1).

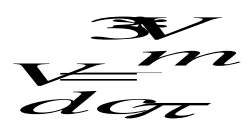

\section{$\mathcal{C}$}

where, $V_{m}$ is peak value of ac voltage

In second stage, DC voltage is converted back to AC voltage of variable magnitude and frequency. In this stage switching pulses are provided in such a manner that to obtain desired value of output voltage. The magnitude of rms AC voltage by using pulse width modulation technique is depending on modulation gain ratio (2).
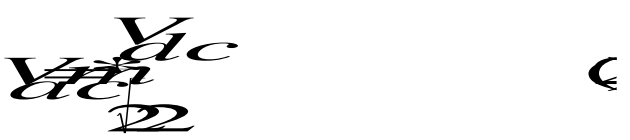

where, $m$ is modulation index

For safe operation of inverting mode, at least three switches must be ON and other should be OFF.

1) No two switches of same leg should not be $\mathrm{ON}$

2) No three switches of same phase should not be ON

III. MATRIX CONVERTER FED INDUCTION MOTOR DRIVE

MC is advanced circuit topology capable of direct power converter which converter power in single stage.

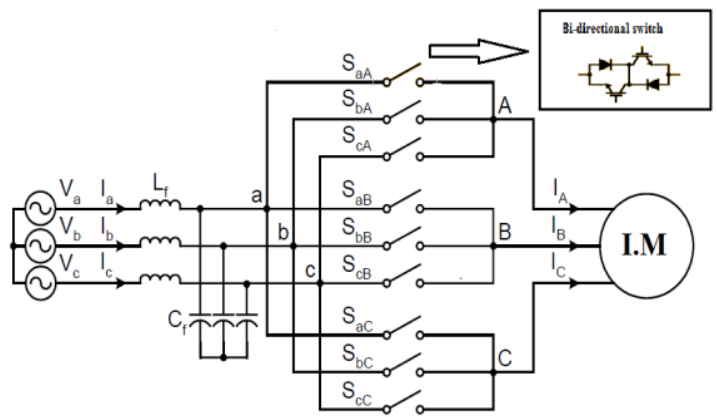

Fig. 2 Matrix converter fed induction motor
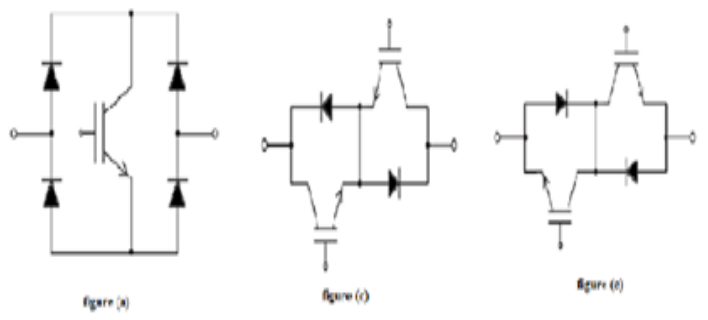

Fig. 3 shows possible configuration of bi-directional switches (a) Diode Embedded Bi-directional, (b)

Common Emitter Bi-directional switch, (c) Common Collector Bi-directional switch

\section{A. Working operation of matrix converter}

Three phase output voltage in terms of switching function (3) are explaining basic working operation of matrix converter [11].

$$
\left[v_{o}\right]=\left[m_{i j}\right] *\left[v_{i n}\right](3)
$$

Here, $, v_{o}, v_{i n}$ are output, input voltage respectively $\mathrm{m}_{i j}$ is modulation index matrix of switch $\mathrm{S}_{\mathrm{ij}}$

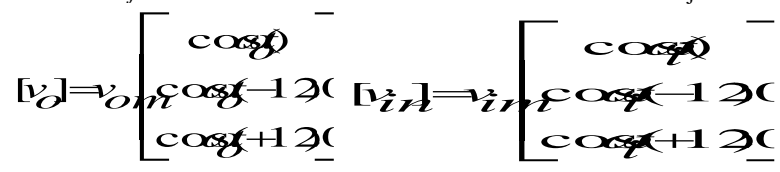

where, $v_{\text {om }}$ and $v_{\text {in }}$ are peak value of input and output voltages respectively. $\omega_{o}$ and $\omega_{i}$ are input and output frequency respectively.

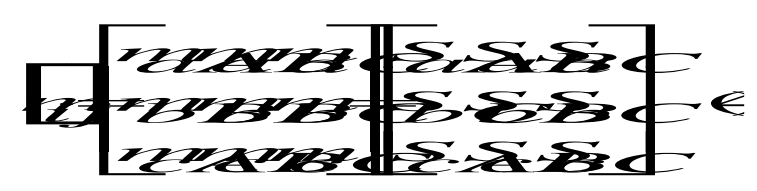

where, $i=a, b, c$ and $j=A, B, C$ are input and output coefficient

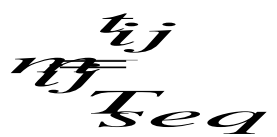

where, $t_{i j}$ is switch ON time for switch $S_{i j}$
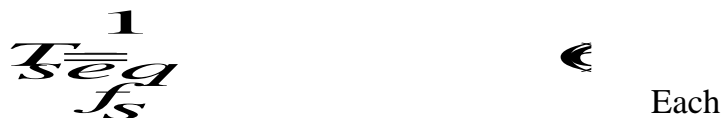

switch is characterized by a switching function(4), defined as follows and can connect or disconnect phase $i$ of the input stage to phase $j$ of the load.

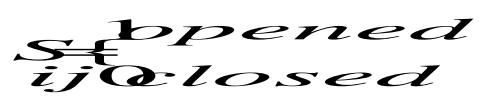

$\varepsilon$

For computing modulation index matrix various modulation technique proposed [13].

\section{SWITCHING STRATEGY FOR CONVENTIONAL CONVERTER}

One of the advantages of conventional DC-link converter is simple switching strategy. To obtain desired value of output voltage of variable frequency and magnitude, the proper switches must be $\mathrm{ON}$ at particular instant. The various modulation schemes investigated for inverting mode operation presented [1] - [2] are:

1) Pulse Width Modulation (PWM)

2) Sinusoidal Pulse Width Modulation(SPWM)

3) Space Vector Pulse Width Modulation(SVPWM) strategy

Among all these switching strategy SPWM is simple than other one. In this modulation scheme sinusoidal waveform (reference signal) compare with triangular wave (carrier) to generate switching pulses. Frequency of triangular waveform decides output frequency of output voltage and peak amplitude of reference waveform decides magnitude of output voltage. 


\section{TABLE I SWITCHING TABLE FOR INVERTER MODE OPERATION}

\begin{tabular}{|c|c|c|c|c|c|c|c|c|c|}
\hline $\begin{array}{c}\text { Sr. } \\
\text { No }\end{array}$ & S1 & S2 & S3 & S4 & S5 & S6 & $\mathrm{V}_{A B}$ & $V_{B C}$ & $V_{A C}$ \\
\hline 1 & ON & ON & OFF & OFF & OFF & ON & V $_{S}$ & 0 & $-V_{S}$ \\
\hline 2 & ON & ON & ON & OFF & OFF & OFF & 0 & $V_{S}$ & $-V_{S}$ \\
\hline 3 & OFF & ON & ON & ON & OFF & OFF & $-V_{S}$ & $V_{S}$ & 0 \\
\hline 4 & OFF & OFF & ON & ON & ON & OFF & $-V_{S}$ & 0 & $V_{S}$ \\
\hline 5 & OFF & OFF & OFF & ON & ON & ON & 0 & $-V_{S}$ & $V_{S}$ \\
\hline 6 & ON & OFF & OFF & OFF & ON & ON & V $_{S}$ & $-V_{S}$ & 0 \\
\hline 7 & ON & OFF & ON & OFF & ON & OFF & 0 & 0 & 0 \\
\hline 8 & OFF & ON & OFF & ON & OFF & ON & 0 & 0 & 0 \\
\hline
\end{tabular}

\section{SWITCHING STRATEGY FOR MATRIX CONVERTER}

One of the limitations of MC is complicated switching strategy which restricted to be used as modern converter for industrial application. Several modulation schemes developed for MC to overcome the limitation of voltage transfer ratio [13]. Three phase output voltage with variable magnitude and unrestricted frequency is obtained by turning ON/OFF appropriated bidirectional switch. Switch ON time calculated for nine BDS on the basis of OAV modulation strategy [14].

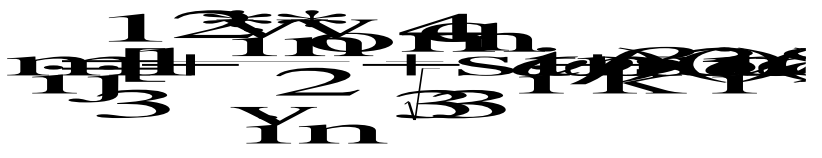

where, $\omega_{i}=2 * \pi^{*} f_{i}$ and $\beta_{k}=0,2 \pi / 3,4 \pi / 3$

Switching logic for safe operation of MC is given in (9) [15]

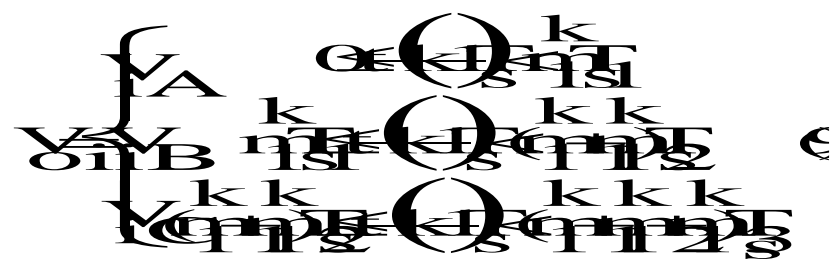

\section{MATLAB SIMULATION OF DC-LINK CONVERTER DRIVING INDUCTION MOTOR}

The simulation was performed with the help of MATLAB/Simulink software. Power circuit of converters has been modelled using power electronic toolbox in Matlab/Simulink. Fig.4 shows the simulink model of conventional DC link converter driving brushless DC motor. The Universal Bridge block 1 provides simulation of three leg diode Rectifier Bridge which is naturally commutated power electronic device (Power diodes). Bridge block provide operation of converting three phase AC supply into DC which is stored in energy storage capacitor. This dc supply converted back into variable AC by inverting bridge block which are three legs of forced commutated power electronics devices such as (IGBT, and MOSFET). Machine block assumes a linear magnetic circuit with no saturation of the stator and rotor. While performing inverting mode operation the gating pulses provide by discrete pulse width generator block. Pulse provided in such manner that at least three switches must be ON by selecting proper modulation index and carrier frequency signal [15].

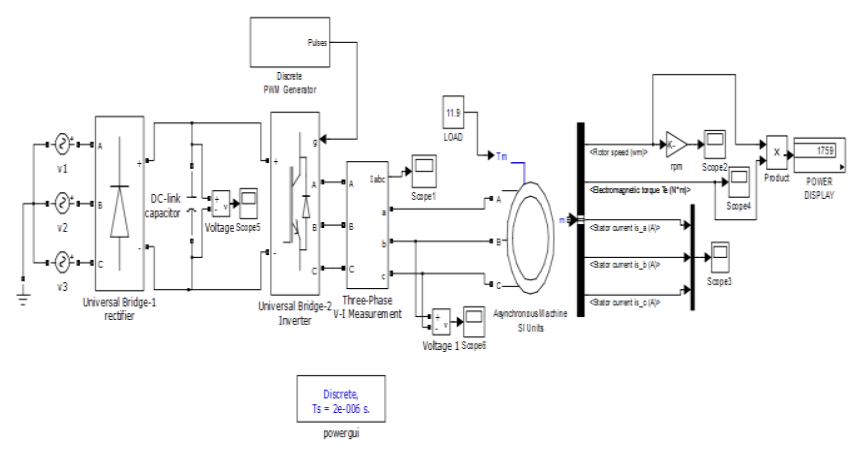

Fig. 4 MATLAB Simulink model of DC- link converter driving Induction motor

A. Results analysis of DC-Link converter fed IM drive Simulation results were given in Fig. 5(a)-5(f). Fig.5 (a) shows three phases line to line voltage. Fig.5 (b) shows the stator currents of the IM for three phases. Fig.5(c) shows speed variation IM, Fig. 5(d) shows the electromagnetic torque variations of IM, Fig. 5 (e) shows pulsation which in between (13.1-10.49) N-m, Fig.5 (f) shows the THD analysis of output side current harmonics distortion and it is found to be around $8.04 \%$.

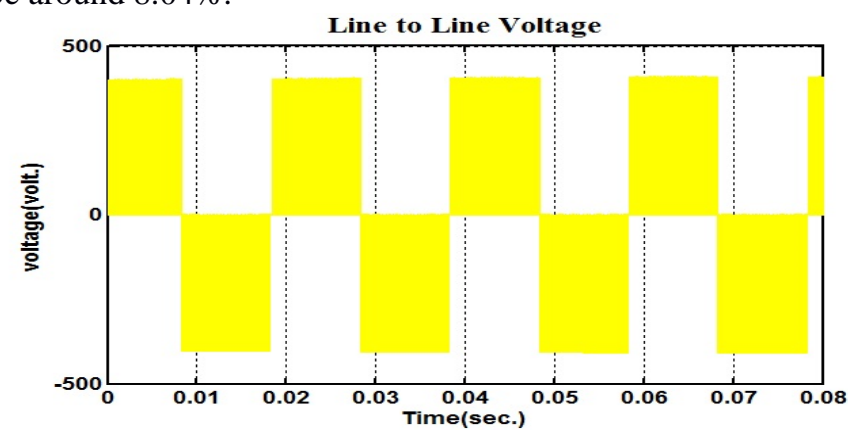

Fig. 5(a) Line to Line voltages (volt.)

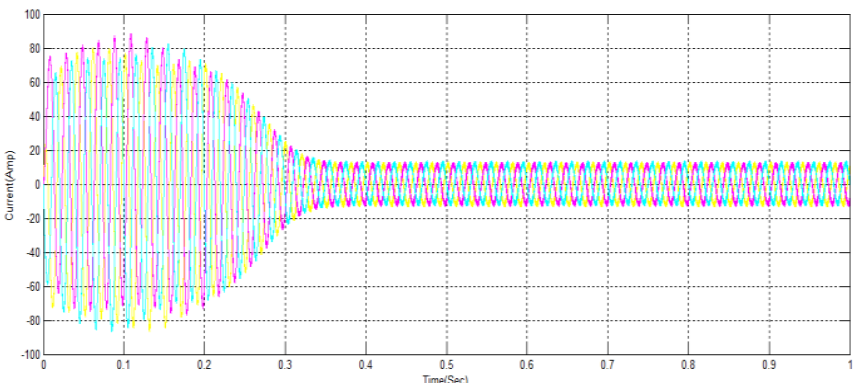

Figure5. (b) stator currents (Amp.)

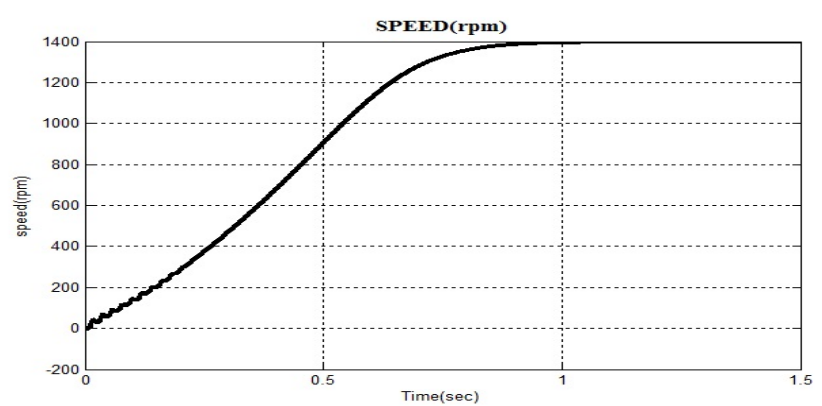

Figure 5(c) Speed (rpm)

Published By:

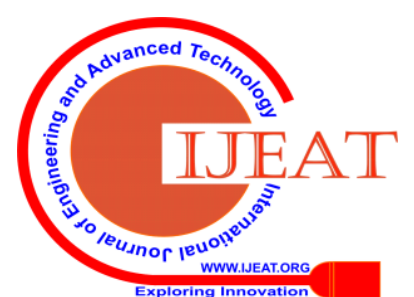




\section{Matrix Converter for Induction Motor Drive}

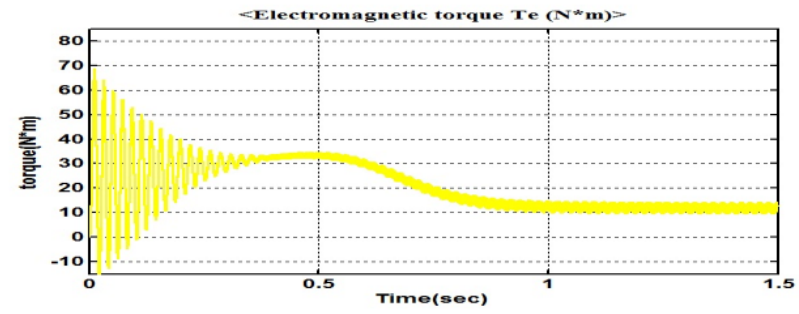

Figure 5(d) Torque (N-m)

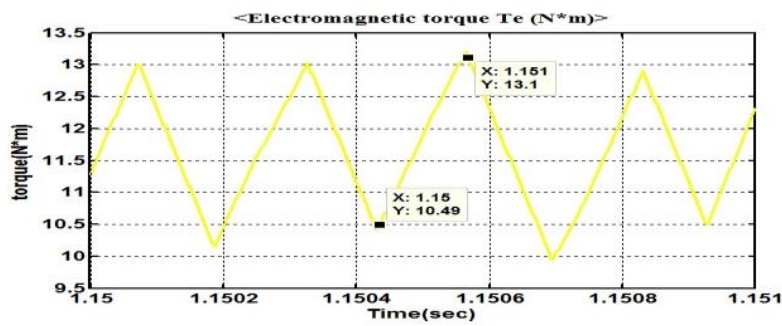

Figure 5(e) Torque pulsation

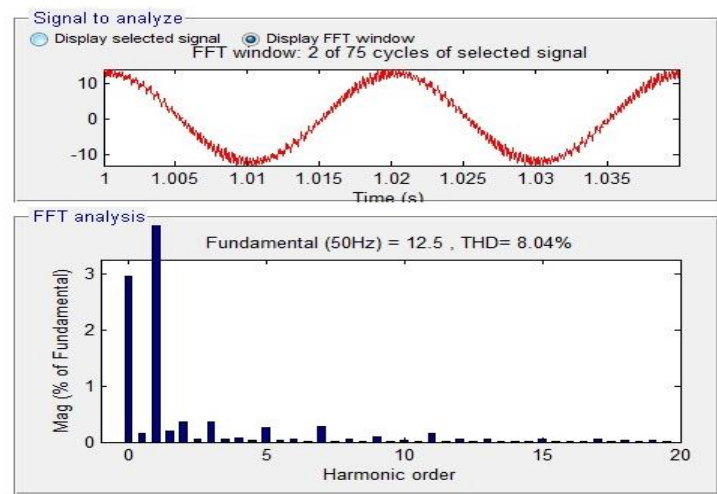

Fig. 5(f) THD Analysis

\section{MATLAB: DRIVING INDUCTION MOTOR}

Simulink model matrix converter design with nine bidirectional switches with common emitter configuration shown in Fig.6 (a).

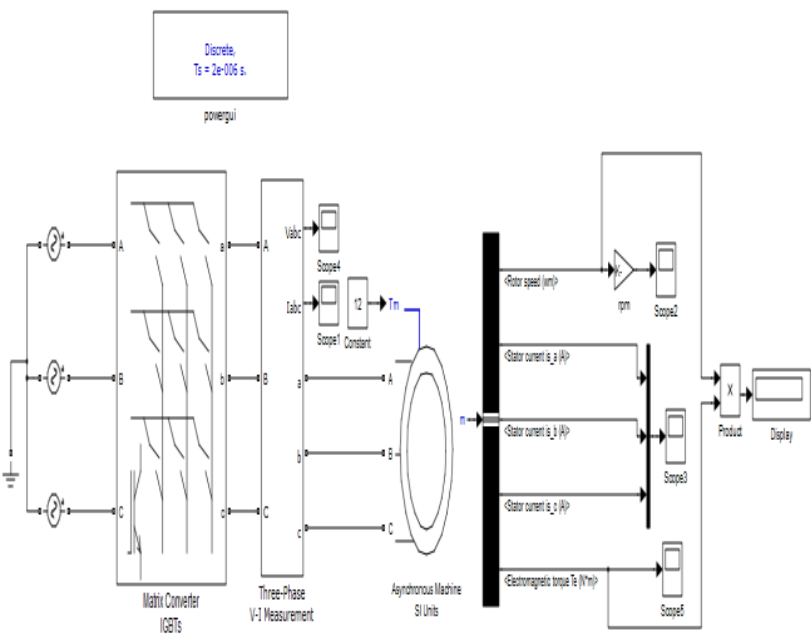

Fig.6. Matrix Converter for Induction Motor

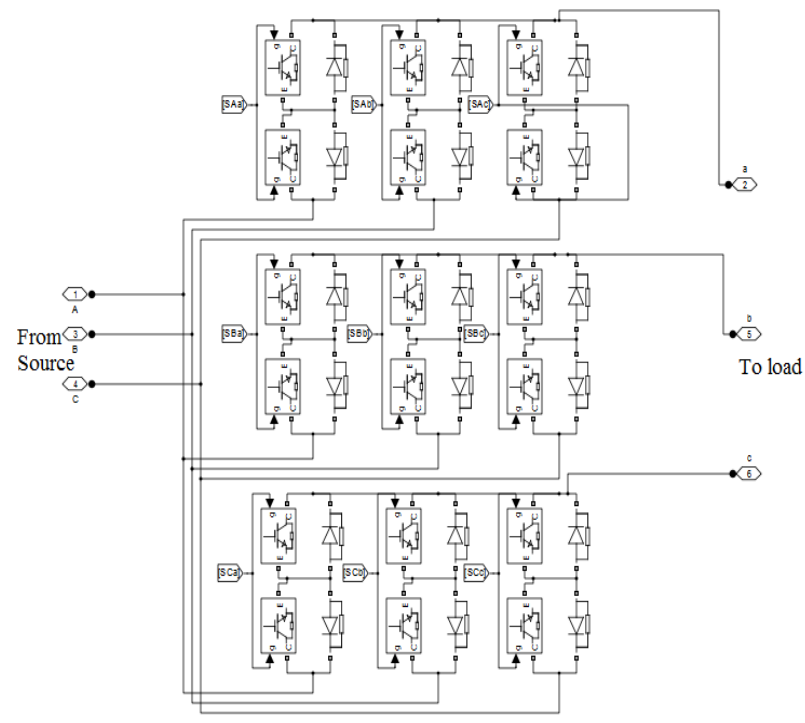

Fig. 7. Three Phase Matrix Converter

The supply current harmonics of converter is reduced by filter so that converter is operated properly.

\section{A. Results analysis of matrix converter fed IM drive}

Fig.7.1 shows three phases line to line voltage. Fig.7.2 represents the stator currents of the I.M. for three phases. Fig.7.3 represent speed variation IM, Fig. 7.4 shows the electromagnetic torque variations of IM, Fig. 7(e) represent torque pulsation is between (12.93-11.01)N-m, Fig.7.6 represent the THD analysis for output side current harmonics distortion and it is found to be around 4.54\%.

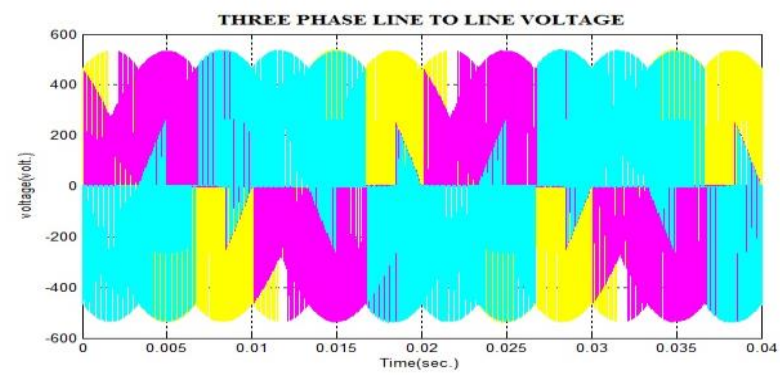

Fig. 7.1 Line to Line voltage (Volt.)

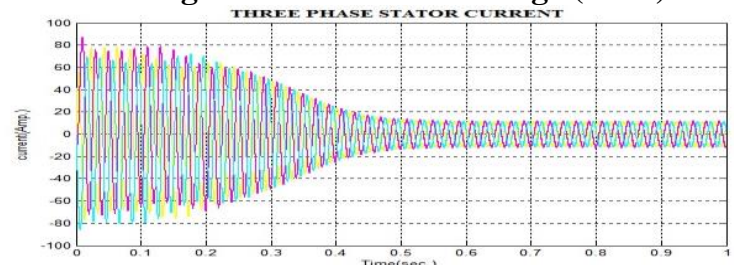

Fig. 7.2Stator currents (Amp.)

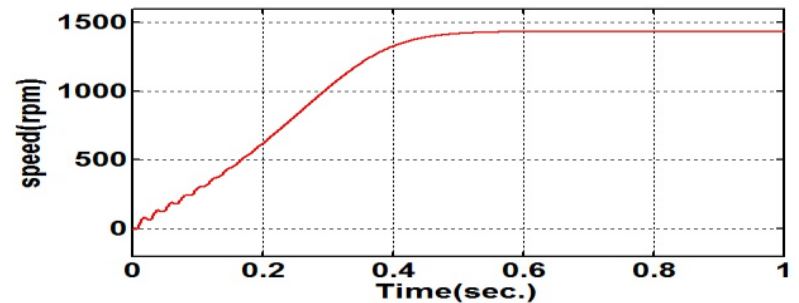

Fig. 7.3 Speed in rpm (rpm)

Published By:

Blue Eyes Intelligence Engineering

\& Sciences $P$

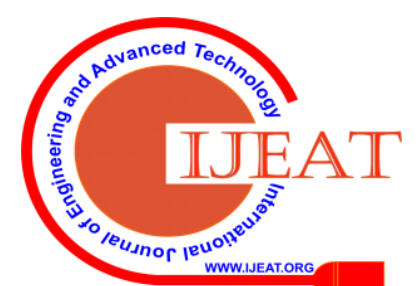




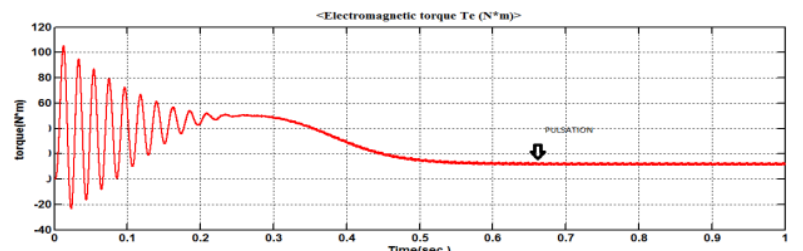

Fig. 7.4 Electromagnetic torque $(\mathrm{N}-\mathrm{m})$

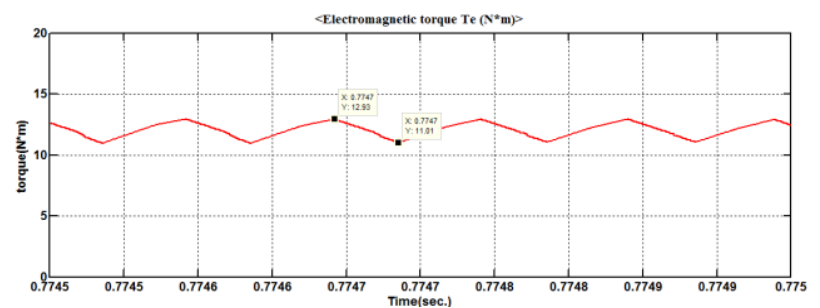

Fig. 7.5 Torque pulsation
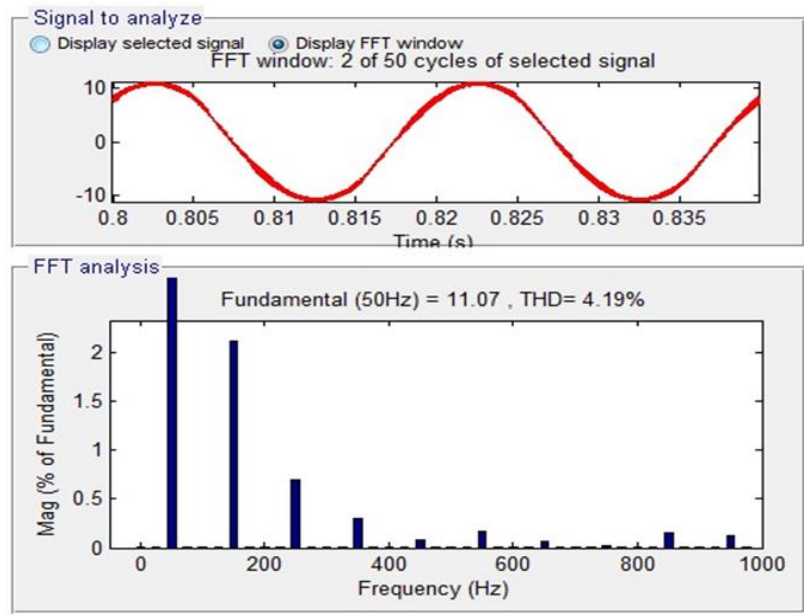

Fig. 7.6 THD Analysis

\section{CONCLUSION}

A paper shows a comparative performance of DC link converter and matrix converter for driving IM to reduce current harmonics distortion. It is noted that DC link converter draws THD reach up to $8.09 \%$ whereas matrix converter $4.14 \%$. The torque pulsation of I.M. produced by matrix converter is lies between (12.93-11.01) N-m which is less than (13.01-10.49) N-m as produced by DC-link converter.

Matrix converter eliminates bulky energy storage capacitor which reduces cost, weight/volume ratio of drive system. A closed mathematical and theoretical description of matrix converter will provide future demands of compact energy saving drive system for industrial use.

\section{REFERENCES}

1. Bimal K. Bose, A text book on, "Modern Power Electronics and AC Drive", $2^{\text {nd }}$ edn, Prentice Hall, New Jersey, 2002., pp. 112-145

2. Bimal K. Bose, A text book on, "Power Electronics and Variable Frequency Drives", $1^{\text {st }}$ edn, Jown Wiley \& Sons, U. K, 1997, pp. 102-108

3. Lipco T. A., (Apr 1998) "Recent Progress in the Development of solid-state AC Motor Drives," IEEE Trans on power electronics .vol.3, no.2, pp. $105-117$.

4. Bhowmik S. and Spee R. (Apr 1993) "A Guide to the Application-Oriented Selection of AC/AC Converter Topologies," IEEE Trans. on power electronics .vol.8, no.2, pp. 156 - 163.

5. Imayavaramban M., Latha K., Uma G and Sunter S., "Matlab/Simulink Implementation for Reducing the Motor Derating and Torque Pulsation of Induction Motor using Matrix Converter," IEEE International Conf. during Apr. 2004.

6. Dubey G. K., A text book on "Power Semiconductor Controlled Drives”, Prentice Hall, New Jersey: 1989, pp.495
7. Krishnam R., A text book on "Electric Motor Drives: Modeling, Analysis, and Control”, Prentice Hall; 2001, pp. 112-140

8. Avadhanlu T. V. and Saxena R. B., (Jan/Feb 1979) "Torque Pulsation Minimization In A Variable Speed Inverter-Fed Induction Motor Drive System," IEEE Trans. on Power Apparatus and Systems, Vol.PAS-98, pp. 1-12

9. Bhowmik S.and Spee R., (Apr. 1993 )“A Guide to the Application-Oriented Selection of AC/AC Converter 1Topologies,'IEEE Trans. on Power Electronics, VOL. 8, NO. 2,pp.-1430-1439.

10. Wheeler P. W., Rodriguez J, Clare J. C. and Empringham L.,( Apr. 2002) "Matrix Converter -A technology review," IEEE Trans. on Indu. Electronic. Vol.49, No.2, pp. 276 - 288.

11. Imayavaramban M., Latha K. and Uma G.,(May 2004) "Analysis of Different Schemes of Matrix Converter with maximum Voltage Conversion ratio", IEEE MELECON 2004, 12-15, Dubrovnik, Croatia1137-1140.

\section{AUTHORS PROFILE}

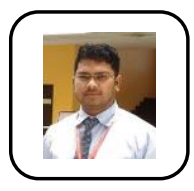

Mr.Pravin Gajananrao Dhawale completed his M-Tech in Electrical Power System from Govt. College of Engineering, Maharashtra and B.E. in Electrical Engineering form RIT. He is Assistant Professor in Sanjay Ghodawat University.He published number of research paper on power system and HVDC. He is the member of Smart grid forum. He won promising young faculty award in SGU, Kolhapur. Currently he is pursuing Ph.D. in Electrical Engineering.

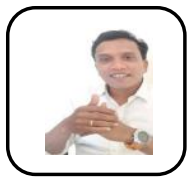

Mr.Sushil Gaurkhede completed his M.Tech in Electrical Power System from Govt. College of Engineering, Amarawati and B.E. in Electrical Engineering. He is the member of ISTE. He is the working with ITM Nagpur. 